\title{
Optical coherence tomography and plaque morphology for revascularization of the superficial femoral artery
}

\author{
Jacob W. Hartwig ${ }^{1}$, Drew J. Braet ${ }^{1}$, Jamie B. Smith ${ }^{2}$, Jonathan Bath ${ }^{1}$, Todd R. Vogel ${ }^{1} \wedge$ \\ ${ }^{1}$ Division of Vascular Surgery, Department of Surgery, University of Missouri, School of Medicine, Columbia, MO, USA; ${ }^{2}$ Department of Family \\ and Community Medicine, University of Missouri, School of Medicine Columbia, Columbia, MO, USA
}

Correspondence to: Todd R. Vogel, MD, MPH. Department of Surgery, Division of Vascular Surgery, University of Missouri Hospital \& Clinics, One Hospital Drive, Columbia, MO 65212, USA. Email: vogeltr@health.missouri.edu.

Background: The optical coherence tomography (OCT) catheter, Ocelot (Avinger Inc., Redwood City, CA), has been utilized to cross Trans-Atlantic Inter-Society Consensus Document (TASC) D lesions. Studies have assessed the characteristics of high-risk plaques in the carotid artery, but few, if any data exist evaluating OCT and plaque morphology in the superficial femoral artery (SFA). This study assessed SFA plaque morphology using OCT and lesion crossing success in chronic total occlusions (CTOs).

Methods: We reviewed patients who underwent attempted infrainguinal revascularization with TASC D CTOs using the Ocelot catheter between June 2014 and June 2018, and recorded demographic information, smoking status, and medical comorbidities. A matched cohort of 44 successfully crossed lesions was compared to 44 that failed; images insufficient for analysis were excluded. The morphology of the plaque was studied using OCT at the proximal cap, midpoint of the lesion, and the distal cap. Morphologic data studied included the intima-media thickness ratio, cross-sectional area of the plaque, and gray-scale median of the plaque.

Results: A total of 140 patients who underwent lower extremity procedures for TASC D lesions of the SFA with OCT imaging were reviewed with a crossing rate of $69.0 \%$. No significant differences were found between crossed and uncrossed lesions for intima-media thickness or cross-sectional area at the proximal cap, the midpoint, or the distal cap. A lower gray-scale median at the proximal cap was associated with the ability to cross the chronic SFA occlusion $(\mathrm{P}=0.05)$. Subgroup analysis stratified by smoking and calcium content also demonstrated that a lower gray-scale median at the proximal cap was associated with the ability to cross the chronic SFA occlusion ( $\mathrm{P}=0.01$ and $\mathrm{P}=0.04$, respectively).

Conclusions: Lower gray-scale median at the proximal cap of a chronic SFA occlusion calculated using OCT images was associated with the ability to successfully cross the lesion. Higher plaque gray-scale median is correlated with increased calcium, greater fibrous tissue, and signal-rich plaques. Gray-scale median in the proximal cap is useful marker to determine plaque composition and subsequent technical success for crossing chronic SFA occlusions. Further studies are needed to fully determine the utility of OCT images to predict successful endovascular revascularization of chronic SFA occlusions.

Keywords: Optical coherence tomography (OCT); superficial femoral artery (SFA); plaque morphology

Submitted May 27, 2020. Accepted for publication Aug 14, 2020.

doi: 10.21037/qims-20-707

View this article at: http://dx.doi.org/10.21037/qims-20-707

^ ORCID: 0000-0001-7782-1593. 


\section{Introduction}

Traditionally, treatment of Trans-Atlantic Inter-Society Consensus Document (TASC) D femoropopliteal lesions required open surgical bypass (1). The advent of newer endovascular image-guided catheters has expanded treatment options of TASC D lesions for patients deemed poor surgical candidates (2). Optical coherence tomography (OCT) uses light to create high-resolution images of vascular structures. OCT imaging measures the difference in time of reflected near-infrared light sent through a tissue sample and reference mirror (3). Current Fourierdomain OCT uses multiple light wavelengths to create an instantaneous image with an axial resolution of $10 \mu \mathrm{m}$ and a radial resolution of $20 \mu \mathrm{m}$ (4). This is more precise than IVUS, which gives a resolution of $150 \mu \mathrm{m}$ (5).

The Ocelot (Avinger Inc., Redwood City, CA) is an image-guided catheter that combines a rotating spiral tip with OCT to transmit real time imaging of intraluminal vessel structures and plaque morphology during revascularization procedures. Studies evaluating OCT imaging catheters and ex vivo histological sections demonstrate that OCT imaging allows for clear delineation of peripheral arterial atherosclerotic diseases components including layered arterial structures (intima, media, and adventitia) and atheromatous components (fibrous, fibro-calcified, and necrotic core plaque sections) (4). Consensus documents found high levels of evidence for the measurement of normal arterial wall layers, fibrous plaque, and fibro calcific plaque structures using OCT imaging (6).

Physicians can use OCT to image arterial structures and plaque morphology to guide treatment during revascularization procedures (7). Studies have demonstrated that the Ocelot catheter can be utilized safely and effectively to cross TASC D lesions $(7,8)$. The CONNECT II trial demonstrated a $97 \%$ total cross rate with a $72 \%$ cross rate using the Ocelot catheter alone (2). There have been studies analyzing the association between preoperative angiography findings, lesion length, and calcium distribution with successful lesion crossing using the Ocelot catheter (9). However, the utility of OCT images acquired during revascularization procedures to predict superficial femoral artery (SFA) lesion crossing has not been previously described. In this study, we used the Ocelot catheter and OCT imaging to evaluate arterial wall structure and plaque morphology in an effort to predict successful crossing of chronic SFA occlusions.

\section{Methods}

\section{Patient selection}

This was a single-center, retrospective review of prospectively collected data. All patients who underwent lower extremity procedures with the Ocelot catheter from June 2014 to June 2018 were included in this study. All patients evaluated in this analysis were TASC D total occlusions of the SFA. The treatment paradigm for all patients with TASC D lesions is to first have attempted crossing using OCT catheter technology, which is considered less invasive, prior to the consideration of open bypass surgery. Success of the Ocelot revascularization procedure was determined by the operating physician's operative note. A propensity score was created based on preoperative comorbidities to allow for a comparable matched group of uncrossed lesions to cross lesions (10). Selected comorbidities were correlated to allow for outcome metrics to assess the effectiveness of OCT and crossing total SFA occlusions based on morphologic plaque criteria. Comorbidities used in matching were characteristics from the medical records including: age, gender, race, and comorbidities including: smoking history, diabetes mellitus, lesion calcification, hypertension, coronary artery disease, and prior cardiac and vascular procedures. A matched cohort consisting of 44 uncrossed SFA lesions and 44 successfully crossed SFA lesions was created based on similar patient characteristics and comorbidities. Six patients with crossed and one patient with uncrossed SFA lesions were excluded from analysis due to OCT imaging lacking clear visualization of layered arterial wall structures.

Patients were considered eligible when diagnosed with chronic limb ischemia grade 3, target vessel diameter $>5 \mathrm{~mm}$, and total occlusion of the target vessel. Patients with a high medical comorbidity burden who desire a minimally invasive endovascular treatment with reduced recovery time were considered for revascularization with the Ocelot catheter (11).

Patient OCT cases were blinded by random number generation and each case was reviewed for selection of stillshots for image analysis (Figure 1). During review, stillshots of the plaque and artery were taken at three points: the proximal cap, the distal cap, and midpoint of the chronic SFA occlusion. Chronic SFA occlusions were crossed in an anterograde manner with start and end points defined as the first visualized plaque and last visualized plaque before lesion crossing or catheter removal due to failure to cross. Different operators would have similar anatomic landmarks defined by 


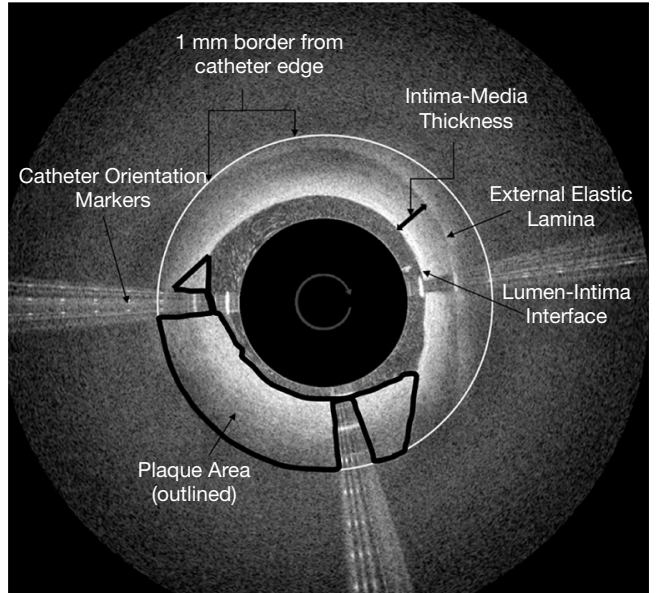

Figure 1 Sample optical coherence tomography (OCT) still-shots for image analysis.

the OCT images yielding comparable start and end points among operators. The proximal cap was defined as the first point on OCT imaging that the plaque and layered arterial structures were visualized. The distal cap was defined as the last point on OCT imaging that the plaque and layered arterial structures were visualized prior to lesion crossing. The midpoint of the lesion was described as the time point midway between the start and end of the chronic SFA occlusion using total catheter crossing time. The proximal and distal caps were selected as measurement points as these areas of a chronic SFA occlusion contain a rigid fibrous cap and often represent the most difficult areas to cross.

The movement of the Ocelot catheter during a chronic SFA occlusion revascularization procedure is not linear. The catheter may traverse a majority of the plaque in a matter of minutes or involve multiple points of stoppage in catheter imaging to allow fluoroscopy to ensure proper positioning of the catheter. Each case is different in this regard, making the selection of the midpoint by distance within the plaque impossible. A midpoint in time of crossing is the best approximation for collecting intra-plaque morphology data in the most objective manner possible. OCT images were reviewed independently by two vascular surgeons who were blinded to the patients and the crossing success. OCT imaging parameters that were clear, objective, and clinically relevant were selected for analysis.

\section{Imaging measurements and definitions}

Each OCT image was analyzed for intima-media thickness, plaque cross sectional area, gray scale mean and median, and the presence of clear calcifications were defined utilizing Adobe photo shop per as per methodology by el-Barghouty et al. (12) Intima-media thickness was defined as the distance between the lumen-intima interface and external elastic lamina spanning the arterial intima and media. The distance between the lumen-intima interface and external elastic lamina was taken at the shortest distance seen on each screenshot with the distance vector directed radially from the center of the catheter crossing profile measured using Adobe Photoshop. Plaque cross sectional area was measured using Adobe Photoshop to outline the plaque from the catheter edge to a $1 \mathrm{~mm}$ defined radial border for analysis $(4,12)$. The Ocelot catheter has a $2 \mathrm{~mm}$ crossing diameter allowing the catheter profile on OCT images to be used as a $2 \mathrm{~mm}$ point of reference during image analysis. $1 \mathrm{~mm}$ was determined as the outer distance for this analysis as tissue penetration for the Ocelot catheter ranges between 1-2 mm dependent on the tissue (3). Plaque area is outlined in Figure 1 as non-layered structure visualized around the Ocelot catheter (12). In contrast to cardiac imaging, the Ocelot catheter cannot visualize the entire SFA occlusive plaque in cross section due to limited tissue penetration of 1 to $2 \mathrm{~mm}$. A $1 \mathrm{~mm}$ radial border from the catheter edge was selected to include as much plaque as possible in our measurements without including "static" signal that can be seen in Figure 1 circumferentially from just outside of the $1 \mathrm{~mm}$ border to the edges of the screenshot.

The same plaque section outlined was also assessed for gray scale mean and median in Adobe Photoshop $(13,14)$. Gray scale median and mean are numerical measurements of signal-poor to signal-rich plaque composition. Each image was analyzed for the presence of clear calcifications seen on OCT imaging. Calcifications were defined as areas of heterogenous, signal-poor plaque with sharply demarcated borders within the plaque area (insert 3). Patients were stratified into two groups based on the outcome of the endovascular procedure (crossed $v s$. uncrossed). In order to compare differences between crossed and uncrossed chronic SFA occlusions, chi square or independent sample t-tests (for continuous variables) were conducted. Additionally, separate stratified analyses were examined controlling for the presence of calcification (none present) and smoking status (current/former smokers). A calcium score was utilized to define thickness and density which was calculated using 2 points for maximum angle $>180^{\circ}, 1$ point for maximum thickness $>0.5 \mathrm{~mm}$ (15). For each comparison, $\mathrm{P}$ values based on the chi-square value or t-value were examined. All 
analyses were performed in SAS version 9.4 (SAS Institute, Cary, NC). The study was approved by the Institutional Review Board of University of Missouri-Columbia (IRB Project number: 2004005) meeting all ethical approval. Written informed consent from the patients was deemed to be unnecessary as this was a retrospective chart review of de-identified records and images.

\section{Results}

There were 140 patients who underwent attempted revascularization of TASC D SFA lesions using the Ocelot catheter between June 2014 and June 2018. Of these cases, 96 of the lesions were successfully crossed and treated, leading to a $69 \%$ rate of crossing the lesions. A cohort of patients with similar demographic characteristics and comorbidities from the successfully crossed group was developed to compare to those individuals in whom crossing the lesion was unsuccessful. During OCT image analysis one uncrossed SFA lesion and six crossed SFA lesions were excluded from analysis due to lack of ample OCT imaging for analysis of arterial layers and plaque composition.

Of the 81 patients (Table 1) adequate for analysis, the average age was $67.8 \pm 8.4,76.5 \%$ were male, and the majority of the patients were Caucasian (86.4\%). In regards to smoking history, $52 \%$ of patients were current smokers, $32 \%$ former smokers, and $16 \%$ were non-smokers. Measured patient comorbidities included for matching were diabetes mellitus (44\%), hypertension (81.5\%), coronary artery disease (54\%), and hyperlipidemia (68\%). Twenty percent of patients had a prior coronary artery bypass graft, while $16.1 \%$ had a prior percutaneous coronary intervention, and $39.5 \%$ had a previous vascular procedure of some kind.

Mean procedure time was $102.4 \pm 33.7$ minutes, fluoroscopy time was $25.6 \pm 15.3$ minutes, crossing time $19.9 \pm 14.9$ minutes, and contrast dose $81.8 \pm 39.1 \mathrm{~mL}$. Contrast utilization in the OCT group was found to be significantly lower $(\mathrm{P}=0.01)$. Matched patient characteristics were similar between the crossed and uncrossed groups analyzed, with the only significant difference being increased contrast dose in the crossed group $92.7 \mathrm{vs}$. $71.9 \mathrm{~mL}(\mathrm{P}=0.01)$.

Intima-media thickness was assessed at the proximal cap, middle, and distal cap of each plaque (Table 2). Overall intima-media thickness decreased from $0.42 \mathrm{~mm}$ at the proximal cap to $0.36 \mathrm{~mm}$ at the distal cap, but was not significantly different between crossed and uncrossed lesions. The cross-sectional plaque area increased from $4.22 \mathrm{~mm}^{2}$ at the proximal cap to $4.33 \mathrm{~mm}^{2}$ at the distal cap, with no significant difference between crossed and uncrossed lesions.

Gray-scale median differed significantly between patients with uncrossed and crossed lesions at the proximal cap $(89.1$ vs. 80 respectively, $\mathrm{P}=0.05$ ). Gray-scale median of crossed and uncrossed lesions was not significant at the middle of the plaque or the distal cap. When controlling for the presence of calcification and smoking history, gray-scale median was significantly higher in uncrossed lesions than crossed lesions at the proximal cap $(\mathrm{P}=0.04$ and $\mathrm{P}=0.01$, respectively), Tables 3,4.

\section{Discussion}

Treatment paradigms for femoropopliteal vascular lesions have transformed significantly over time. Surgical bypasses have been replaced by various less invasive endovascular treatment options. Intraluminal recanalization of chronic SFA occlusions is now possible with image-guided catheter technology, such as the Ocelot catheter (2). The Ocelot catheter has shown early clinical results suggestive of a viable treatment option of chronic SFA occlusions with crossing success in $72 \%$ of cases and up to $97 \%$ with the addition of an assist re-entry device $(2,7)$. In our cohort we encountered a $69 \%$ cross rate which was similar to those previously reported in the literature $(7,9)$. Although there was no significant difference between the intima-media thickness or cross sectional plaque area of patients with successfully crossed and uncrossed SFA lesions, the grayscale median differed significantly between patients with uncrossed and crossed superficial femoral arteries at the proximal cap of the lesion.

OCT imaging has been applied to predict clinical outcomes in other clinical applications. OCT imaging has been used to identity thin-cap fibroatheroma, intra-stent thrombus, and intra-stent dissection in coronary arteries, which were predictive of peri-procedural myocardial infarction and tissue necrosis post-percutaneous coronary intervention (PCI) (16). Furthermore, OCT imaging was used to identify stent length selection, stent position, and stent malposition during PCI, ultimately leading to procedural changes in $57 \%$ of cases before and $27 \%$ after PCI (17). OCT imaging provides clinicians higher resolution views of vascular structures than have been available in the past with ultrasound applications (18). Despite the positive clinical outcomes possible with use of 
Table 1 Demographics

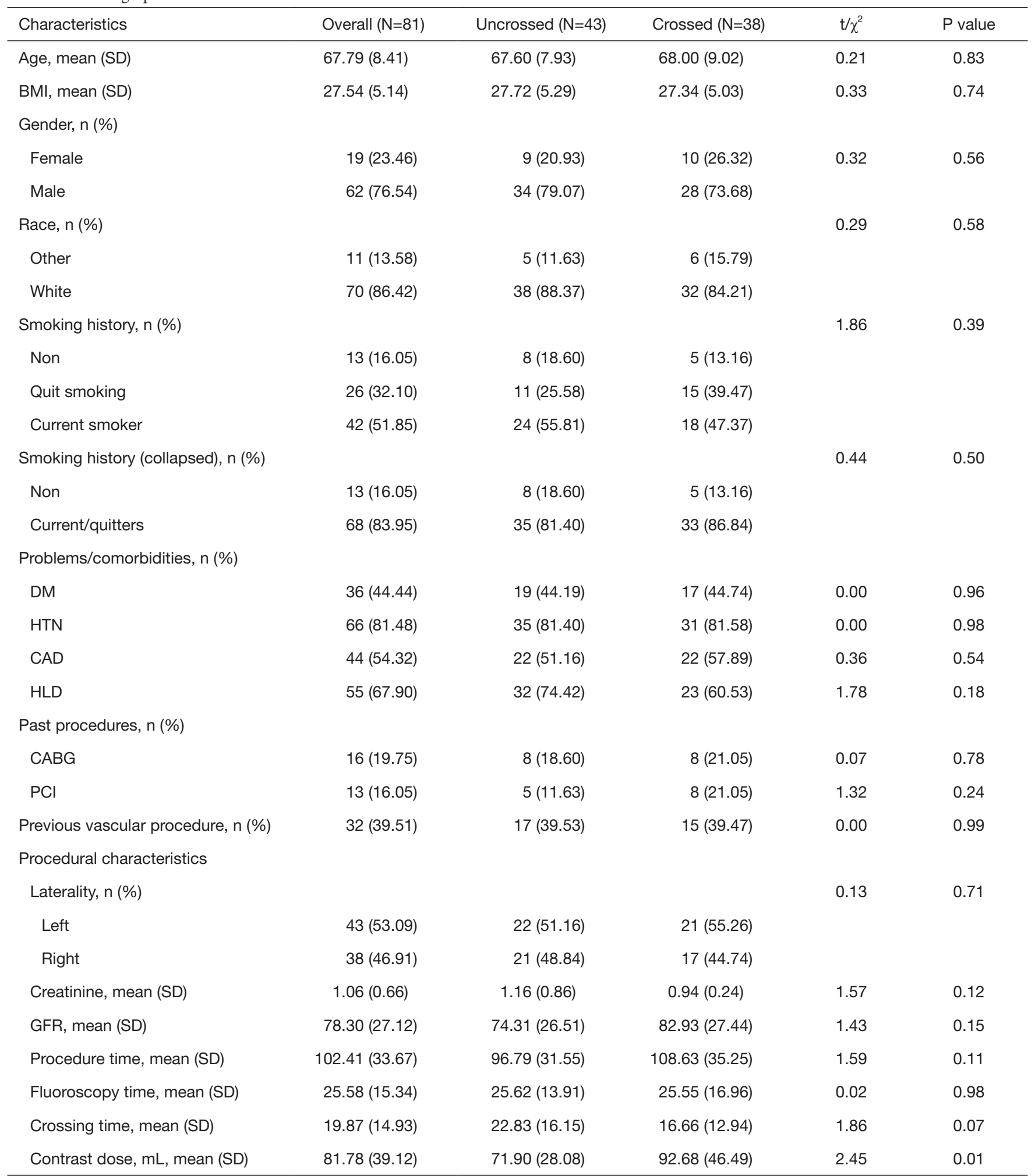

t, t-statistic; $\chi^{2}$, chi square (comparing crossed/uncrossed). DM, type 1 and 2 diabetes mellitus; HTN, hypertension; CAD, coronary artery disease; HLD, hyperlipidemia; CABG, coronary artery bypass grafting; GFR, glomerular filtration rate; PCI, post-percutaneous coronary intervention. 
Table 2 Outcomes

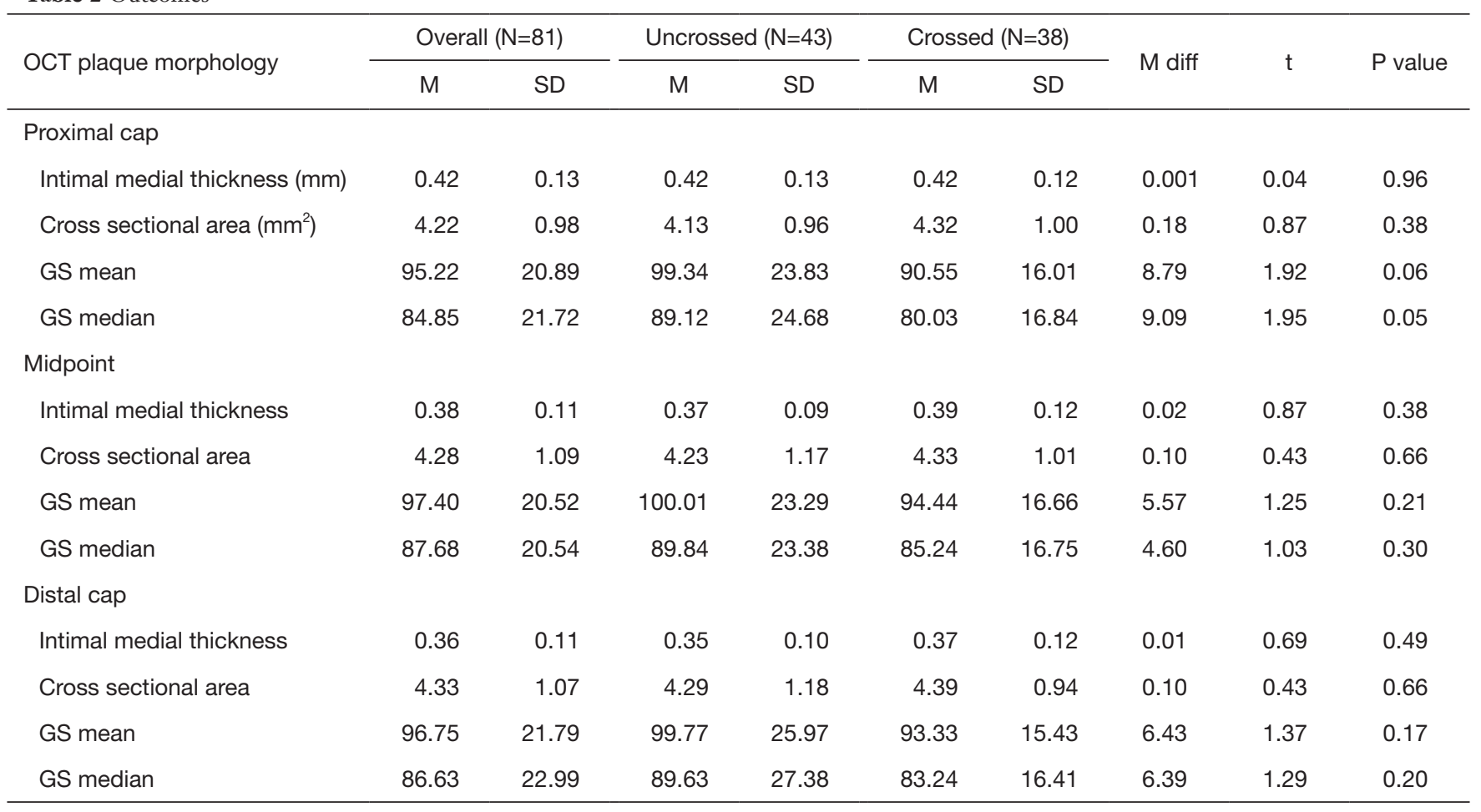

t, t-statistic; M diff, difference between crossed/uncrossed means. GS, grayscale.

Table 3 Outcomes no calcium present

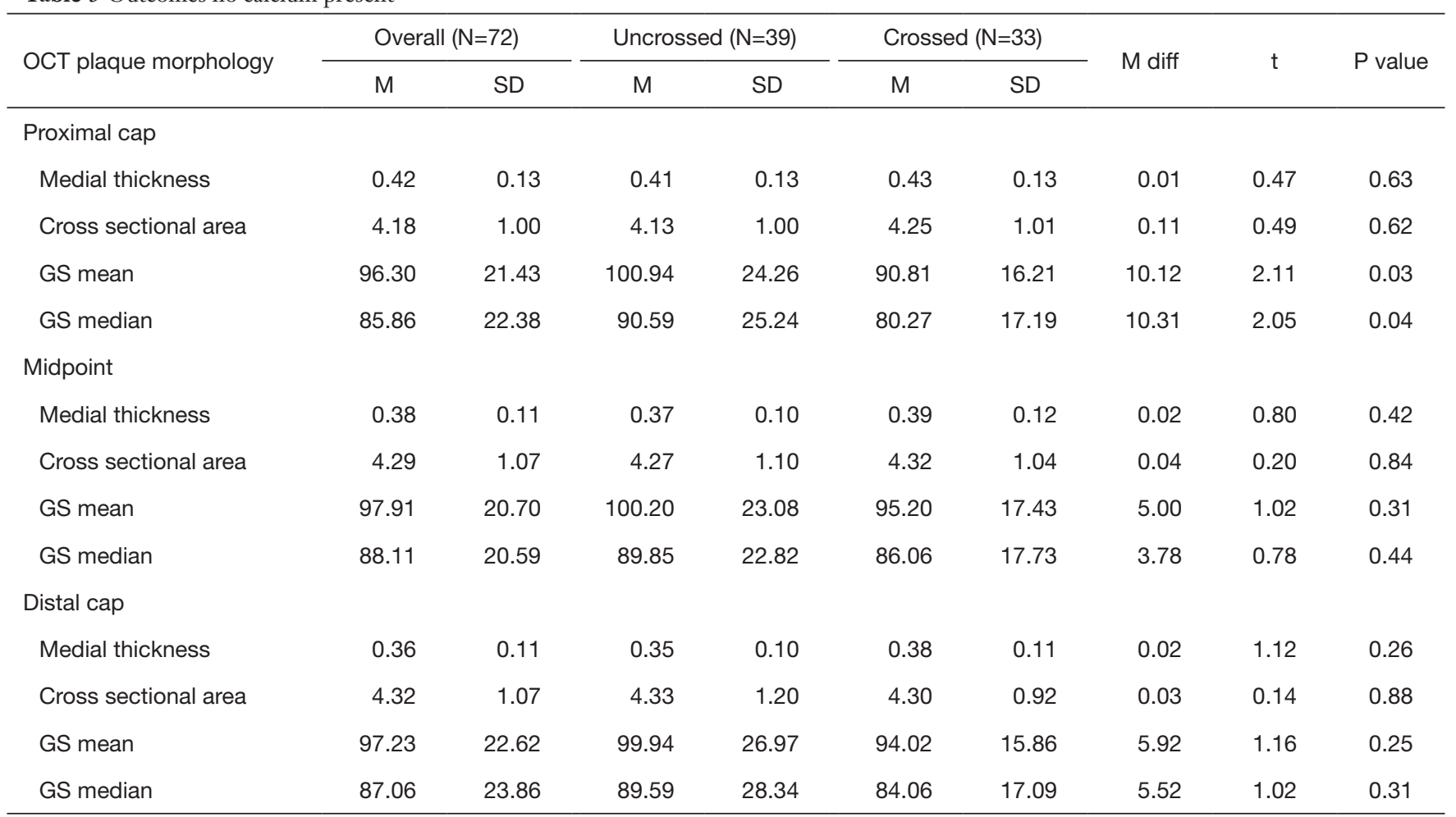

t, t-statistic; M diff, difference between crossed/uncrossed means. GS, grayscale. 
Table 4 Outcomes smokers only

\begin{tabular}{|c|c|c|c|c|c|c|c|c|c|}
\hline OCT plaque morphology & \multicolumn{2}{|c|}{ Overall $(\mathrm{N}=68)$} & \multicolumn{2}{|c|}{ Uncrossed $(\mathrm{N}=35)$} & \multicolumn{2}{|c|}{ Crossed (N=33) } & M diff & $t$ & $P$ value \\
\hline \multicolumn{10}{|l|}{ Start } \\
\hline Medial thickness & 0.43 & 0.13 & 0.43 & 0.13 & 0.43 & 0.12 & 0.00 & 0.03 & 0.97 \\
\hline Cross sectional area & 4.10 & 0.97 & 4.03 & 0.99 & 4.19 & 0.97 & 0.16 & 0.68 & 0.49 \\
\hline GS median & 87.28 & 22.15 & 93.57 & 24.61 & 80.61 & 17.16 & 12.96 & 2.53 & 0.01 \\
\hline \multicolumn{10}{|l|}{ Middle } \\
\hline Medial thickness & 0.38 & 0.11 & 0.38 & 0.10 & 0.39 & 0.12 & 0.01 & 0.60 & 0.54 \\
\hline Cross sectional area & 4.19 & 0.84 & 4.14 & 0.83 & 4.24 & 0.87 & 0.10 & 0.52 & 0.60 \\
\hline \multicolumn{10}{|l|}{ End } \\
\hline Medial thickness & 0.36 & 0.11 & 0.36 & 0.10 & 0.36 & 0.11 & 0.00 & 0.14 & 0.88 \\
\hline Cross sectional area & 4.29 & 1.07 & 4.21 & 1.18 & 4.37 & 0.94 & 0.16 & 0.61 & 0.54 \\
\hline GS mean & 98.16 & 21.87 & 102.55 & 26.07 & 93.51 & 15.36 & 9.04 & 1.75 & 0.08 \\
\hline GS median & 87.74 & 23.22 & 91.97 & 27.78 & 83.24 & 16.40 & 8.73 & 1.59 & 0.11 \\
\hline
\end{tabular}

t, t-statistic; M diff, difference between crossed/uncrossed means. GS, grayscale.

the OCT catheter in coronary procedures, there have not yet been investigations into the use of OCT imaging of lower extremity arterial structures and plaque morphology with the goal of predicting clinical outcomes of successful crossing of chronic SFA occlusions. This study hopes to expand the demonstrated use of OCT imaging from point of care clinical guidance to a group of clinical markers to assess revascularization success rates when evaluating plaque morphology.

Carotid intima-media thickness is a well-described, reproducible measurement that is predictive of full body atherosclerotic and coronary artery plaque burden $(19,20)$. A larger carotid intima-media thickness is associated with increased plaque burden and increased risk of ischemic coronary disease (21). Increased intima-media thickness within chronic SFA occlusions was not found to be predictive of SFA occlusion crossing failure in this present study. The Ocelot catheter gives an axial cross-section of tissue being crossed, not a forward-facing view of tissue that the spiral catheter tip is currently traversing. Changes in intima-media thickness and plaque morphology in an uncrossed SFA occlusion distal cap would not be captured by OCT imaging during revascularization procedures.

The gray-scale median has been used previously to associate plaque composition with different symptomatic presentations of carotid arterial stenosis (22-24). Multiple studies have found that in patients with greater than $50 \%$ internal carotid artery stenosis; more echolucent plaque structure with a lower gray-scale median was associated with symptomatic disease and neurologic signs This is consistent with studies of coronary artery applications of OCT finding thin cap fibroatheromas to be associated with increased risk of plaque rupture and peri-procedural myocardial infarction $(16,21)$. Within a coronary or carotid non-occlusive lesion, lipid-rich thin cap plaques are more prone to rupture and thrombus formation leading to myocardial or cerebral infarction for coronary and carotid plaques respectively. In contrast, occlusive lesions in the SFA are more difficult to cross when the cross sectional lesion is more calcified on angiography (9). Lipid-rich thin cap atheromas have a greater risk of rupture in coronary arteries. In chronic total occlusions (CTOs) of the SFA, we believe that more fibrotic and calcific plaques represent more difficult lesions to cross. Calcifications have a heterogenous mix of signal-rich and 
signal-poor plaque areas on OCT. Fibrotic plaque areas have more uniform signal-rich areas. Fibrocalcific plaques demonstrate sections of calcified and fibrotic plaque. Calcifications show heterogeneous signals on OCT imaging, while areas of fibrosis are signal-rich on OCT imaging, which would result in higher average gray-scale median values of plaque cross sectional area $(3,6)$. A lower grayscale median may be associated with plaques containing less calcification and fibrocalcific plaque components and more lipid components that are more easily crossed by the Ocelot catheter. This present study found lower gray-scale median within the proximal cap associated with successful SFA crossing by the Ocelot catheter and this finding was more pronounced in patients that did not have calcific lesions. Higher gray-scale median at the proximal cap is associated with fibrocalcific plaque contents, making these chronic SFA occlusions less likely to be successfully crossed by the Ocelot catheter.

Currently, OCT imaging analysis of gray-scale median is performed after the revascularization procedure. This present study can serve as a proof of concept of imaging analysis parameters that can be used to compare crossed and uncrossed chronic SFA occlusions. Future changes to OCT imaging software to measure gray-scale median during revascularization procedures may lead to greater clinical utility. This could include changing to a different re-entry device sooner or aborting the endovascular treatment for a surgical bypass to limit procedure times, contrast and fluoroscopy doses. Furthermore, this study demonstrates that there is a significant difference between the proximal and distal caps within SFA total occlusions. Patients with lower gray-scale median values at the proximal cap are more likely to have technical success of lesion crossing by the Ocelot catheter within the SFA.

Limitations to this study include that it was a single center and retrospective review with a relatively small sample size. There was no assessment of patency rates or long-term clinical outcomes of the chronic SFA occlusions. The non-linear progression of the Ocelot catheter through the lesion over the course of a procedure makes it impossible to sample from the midpoint by distance for each patient, leading to variation within the intra-plaque measurements acquired. The Ocelot catheter does not have forward facing OCT imaging, so plaque areas unable to be crossed by the catheter were not available for analysis. Stillshots analyzed from three points within the lesion only represent a distinct portion of the overall plaque imaging captured by each Ocelot case.

\section{Conclusions}

OCT imaging provides high-resolution real-time imaging of intravascular lesions that may be used in real time to guide clinical decision-making and has been found to lower overall contrast utilization during revascularization procedures (17). Imaging markers of arterial wall and plaque morphology at the proximal cap have the potential to enhance the clinical utility of the Ocelot OCT catheter. This is the first study, to our knowledge, to demonstrate that a lower gray-scale median value at the proximal cap of a chronic SFA occlusion is associated with successful crossing of the SFA occlusion. Higher gray-scale median values likely signify more signal-rich plaque composition representing denser fibrous plaque tissue. Further studies are needed to refine these parameters and assess the utility of real-time analysis of OCT images to predict successful revascularization for CTOs within the SFA.

\section{Acknowledgments}

Funding: None.

\section{Footnote}

Conflicts of Interest: All authors have completed the ICMJE uniform disclosure form (available at http://dx.doi. org/10.21037/qims-20-707). The authors have no conflicts of interest to declare.

Ethical Statement: The study was approved by the Institutional Review Board of University of MissouriColumbia (IRB Project number: 2004005) meeting all requirements for approval.

Open Access Statement: This is an Open Access article distributed in accordance with the Creative Commons Attribution-NonCommercial-NoDerivs 4.0 International License (CC BY-NC-ND 4.0), which permits the noncommercial replication and distribution of the article with the strict proviso that no changes or edits are made and the original work is properly cited (including links to both the formal publication through the relevant DOI and the license). See: https://creativecommons.org/licenses/by-nc-nd/4.0/.

\section{References}

1. Hardman RL, Jazaeri O, Yi J, Smith M, Gupta R. 
Overview of classification systems in peripheral artery disease. Semin Intervent Radiol 2014;31:378-88.

2. Selmon MR, Schwindt AG, Cawich IM, Chamberlin JR, Das TS, Davis TP, George JC, Janzer SF, Lopez LA, McDaniel HB, McKinsey JF, Pigott JP, Raja ML, Reimers B, Schreiber TL. Final results of the Chronic Total Occlusion Crossing With the Ocelot System II (CONNECT II) study. J Endovasc Ther 2013;20:770-81.

3. Dohad S, Shao J, Cawich I, Kankaria M, Desai A. Diagnostic imaging capabilities of the Ocelot -Optical Coherence Tomography System, ex-vivo evaluation and clinical relevance. BMC Med Imaging 2015;15:57.

4. Abtahian F, Jang IK. Optical coherence tomography: basics, current application and future potential. Curr Opin Pharmacol 2012;12:583-91.

5. Bhatt H, Janzer S, George JC. Crossing techniques and devices in femoropopliteal chronic total occlusion intervention. Cardiovasc Revasc Med 2017;18:623-631.

6. Tearney GJ, Regar E, Akasaka T, Adriaenssens T, Barlis P, Bezerra HG, Bouma B, Bruining N, Cho JM, Chowdhary S, Costa MA, de Silva R, Dijkstra J, Di Mario C, Dudek D, Falk E, Feldman MD, Fitzgerald P, Garcia-Garcia HM, Gonzalo N, Granada JF, Guagliumi G, Holm NR, Honda Y, Ikeno F, Kawasaki M, Kochman J, Koltowski L, Kubo T, Kume T, Kyono H, Lam CC, Lamouche G, Lee DP, Leon MB, Maehara A, Manfrini O, Mintz GS, Mizuno K, Morel MA, Nadkarni S, Okura H, Otake H, Pietrasik A, Prati F, Räber L, Radu MD, Rieber J, Riga M, Rollins A, Rosenberg M, Sirbu V, Serruys PW, Shimada K, Shinke T, Shite J, Siegel E, Sonoda S, Suter M, Takarada S, Tanaka A, Terashima M, Thim T, Uemura S, Ughi GJ, van Beusekom HM, van der Steen AF, van Es GA, van Soest G, Virmani R, Waxman S, Weissman NJ, Weisz G; International Working Group for Intravascular Optical Coherence Tomography (IWG-IVOCT). Consensus standards for acquisition, measurement, and reporting of intravascular optical coherence tomography studies: a report from the International Working Group for Intravascular Optical Coherence Tomography Standardization and Validation. J Am Coll Cardiol 2012;59:1058-72.

7. Schaefers JF, Schwindt AG, Maritati G, Torsello G, Pannucio G. Outcome After Crossing Femoropopliteal Chronic Total Occlusions Based on Optical Coherence Tomography Guidance. Vasc Endovascular Surg 2018;52:27-33.

8. Schwindt A, Reimers B, Scheinert D, Selmon M, Pigott JP, George JC, Robertson G, Janzer S, McDaniel HB, Shrikhande GV, Torsello G, Schaefers J, Saccà S, Versaci
F. Crossing chronic total occlusions with the Ocelot system: the initial European experience. EuroIntervention 2013;9:854-62.

9. Kim RJ, Smith JB, Vogel TR. Preoperative assessment of computerized tomography angiography to predict success for crossing long Trans-Atlantic Inter-Society Consensus D lesions using the optical coherence tomography catheter. Vascular 2018;26:362-7.

10. Little RJ, Rubin DB. Causal effects in clinical and epidemiological studies via potential outcomes: concepts and analytical approaches. Annu Rev Public Health 2000;21:121-45.

11. Nowakowski P, Buszman P, Janas A, Kieszs S, Buszman P. Five-year outcomes after revascularization of superficial femoral artery occlusion using Ocelot catheter. Postepy Kardiol Interwencyjnej 2019;15:472-6.

12. el-Barghouty N, Geroulakos G, Nicolaides A, Androulakis A, Bahal V. Computer-assisted carotid plaque characterisation. Eur J Vasc Endovasc Surg 1995;9:389-93.

13. Giannoukas AD, Sfyroeras GS, Griffin M, Saleptsis V, Nicolaides AN. Association of plaque echostructure and cardiovascular risk factors with symptomatic carotid artery disease. J Cardiovasc Surg (Torino) 2010;51:245-51.

14. Ariyoshi K, Okuya S, Kunitsugu I, Matsunaga K, Nagao Y, Nomiyama R, Takeda K, Tanizawa Y. Ultrasound analysis of gray-scale median value of carotid plaques is a useful reference index for cerebro-cardiovascular events in patients with type 2 diabetes. J Diabetes Investig 2015;6:91-7.

15. Fujino A, Mintz GS, Matsumura M, Lee T, Kim SY, Hoshino M, Usui E, Yonetsu T, Haag ES, Shlofmitz RA, Kakuta T, Maehara A. A new optical coherence tomography-based calcium scoring system to predict stent underexpansion. EuroIntervention 2018;13:e2182-9.

16. Porto I, Di Vito L, Burzotta F, Niccoli G, Trani C, Leone AM, Biasucci LM, Vergallo R, Limbruno U, Crea F. Predictors of periprocedural (type IVa) myocardial infarction, as assessed by frequency-domain optical coherence tomography. Circ Cardiovasc Interv 2012;5:89-96, S1-6.

17. Wijns W, Shite J, Jones MR, Lee SW, Price MJ, Fabbiocchi F, Barbato E, Akasaka T, Bezerra H, Holmes D. Optical coherence tomography imaging during percutaneous coronary intervention impacts physician decision-making: ILUMIEN I study. Eur Heart J 2015;36:3346-55.

18. Pavillard E, Sewall L. A post-market, multi-vessel evaluation of the imaging of peripheral arteries for 
diagnostic purposeS comparing optical Coherence tomogrApy and iNtravascular ultrasound imaging (SCAN). BMC Med Imaging 2020;20:18.

19. Den Ruijter HM, Peters SA, Anderson TJ, Britton AR, Dekker JM, Eijkemans MJ, Engström G, Evans GW, de Graaf J, Grobbee DE, Hedblad B, Hofman A, Holewijn S, Ikeda A, Kavousi M, Kitagawa K, Kitamura A, Koffijberg H, Lonn EM, Lorenz MW, Mathiesen EB, Nijpels G, Okazaki S, O'Leary DH, Polak JF, Price JF, Robertson C, Rembold CM, Rosvall M, Rundek T, Salonen JT, Sitzer M, Stehouwer CD, Witteman JC, Moons KG, Bots ML. Common carotid intima-media thickness measurements in cardiovascular risk prediction: a meta-analysis. JAMA 2012;308:796-803.

20. Coll B, Feinstein SB. Carotid intima-media thickness measurements: techniques and clinical relevance. Curr Atheroscler Rep 2008;10:444-50.

Cite this article as: Hartwig JW, Braet DJ, Smith JB, Bath J, Vogel TR. Optical coherence tomography and plaque morphology for revascularization of the superficial femoral artery. Quant Imaging Med Surg 2021;11(1):290-299. doi: 10.21037/qims-20-707
21. Kubo T, Imanishi T, Takarada S, Kuroi A, Ueno S, Yamano T, Tanimoto T, Matsuo Y, Masho T, Kitabata H, Tsuda K, Tomobuchi Y, Akasaka T. Assessment of culprit lesion morphology in acute myocardial infarction: ability of optical coherence tomography compared with intravascular ultrasound and coronary angioscopy. J Am Coll Cardiol 2007;50:933-9.

22. Nezu T, Hosomi N, Aoki S, Matsumoto M. Carotid Intima-Media Thickness for Atherosclerosis. J Atheroscler Thromb 2016;23:18-31.

23. Elatrozy T, Nicolaides A, Tegos T, Griffin M. The objective characterisation of ultrasonic carotid plaque features. Eur J Vasc Endovasc Surg 1998;16:223-30.

24. Lundberg C, Hansen T, Ahlstrom H, Lind L, Wikstrom J, Johansson L. The relationship between carotid intimamedia thickness and global atherosclerosis. Clin Physiol Funct Imaging 2014;34:457-62. 